\title{
Accounting Information System Design under Network Environment
}

\author{
Yan Li \\ School of management, Wuhan University of technology, Wuhan, 430070, China
}

Keywords: Network, accounting, information systems.

\begin{abstract}
With the development of information technology, production and business activities of enterprises have tremendous changes. In recent years, with the rapid development of Internet, ecommerce became popular, the transaction using the Internet has become an inevitable trend. With the development of the network at the same time, users of accounting information has become more widespread, the means and methods of supervision of accounting operations need more advanced, based on this case, the network accounting emerged. This paper aims to design accounting information system under the background.
\end{abstract}

\section{Introduction}

First, there is a network of accounting changes the mode of operation of accounting, and accounting by manual operation stage transformed into computer operations. The emergence of financial software, and change the status on the separation of the financial and business operations in the manual, to achieve the integration of financial operations management. Secondly, in the network environment, managers can learn enterprise business and financial operations of the accounting through the network information system anytime and anywhere, also help managers control and supervision of the financial. Finally, in the network environment, accounting information does not appear in the form of information silos, the accounting information systems and internal and external are closely linked as a whole, information users can get the accounting information they need through a network. Therefore, the development of network technology to corporate accounting has brought great convenience. At this stage, the accounting system is not perfect, especially in the Internet platform, system security issues more prominent, the paper system is designed to do some analysis.

\section{Systems Analysis}

In recent years, many domestic companies has grown, the competition becomes more intense, if companies want to win in the competition, the need to strengthen financial management, centralized accounting system is a novel means to achieve centralized management of funds, has been adopted by the majority enterprise Group, the application of the accounting system is necessary.

Design of accounting information systems also need to follow certain principles, they are shown below:

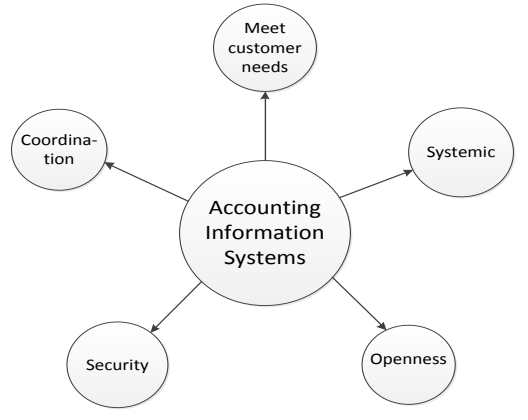

Fig.1 accounting information system design principles

To design accounting information system must determine the system design goals and principles. 
The overall objective of the Group corporate network accounting information system are: make corporate finance centralized management as a prerequisite ,make WAN technologies as the basis ,make accounting as the core, decision support oriented, to build a financial business collaboration, data set, functional integration, application real-time, all-round, multi-angle accounting information network platform.

After a clear goal, to focus on the central objective, make a detailed plan, and have scientific and rational steps to design a system of accounting information.

Specific steps are shown in Figure 2.

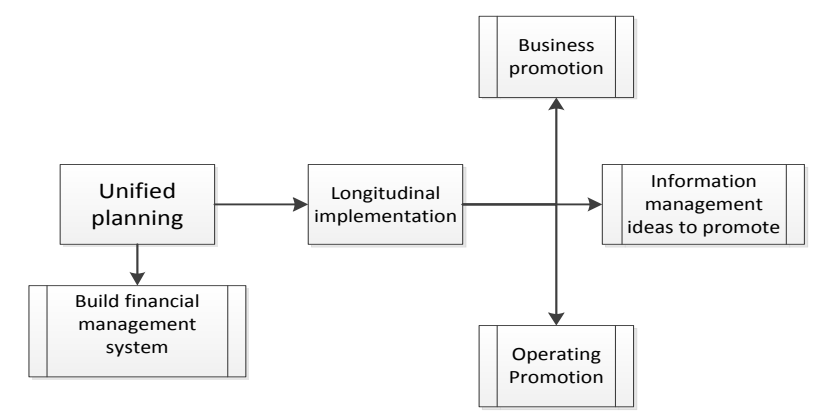

Fig. 2: Accounting information system application process

Shown in Figure 2, the accounting information system applications in the enterprise can be roughly summarized as follows: First, the overall planning, this step must be to build a highly integrated information management system, when the system is completed, it must be longitudinal promotion in order to make full use of the system, including its business, operations and information technology to promote ideological.

\section{System Design}

\section{Function module design}

Accounting information system design under network environment is based IT platform software design, and therefore follow the common software platform system design process, In addition to requirements analysis and other preparatory work, the next step is software selection. The next is to determine the flow of transactions processing, select the software architecture, data in a centralized manner, network architecture and modular design.

When the software selection, because the accounting system of commercial confidentiality, so the best way is to set up their own business development team, rather than choose to outsource.

After determining transaction processing, accounting information system functions no longer just confined to the daily accounting treatment, but with the company's business processing systems complement each other, as a flexible and powerful information systems. As shown below:

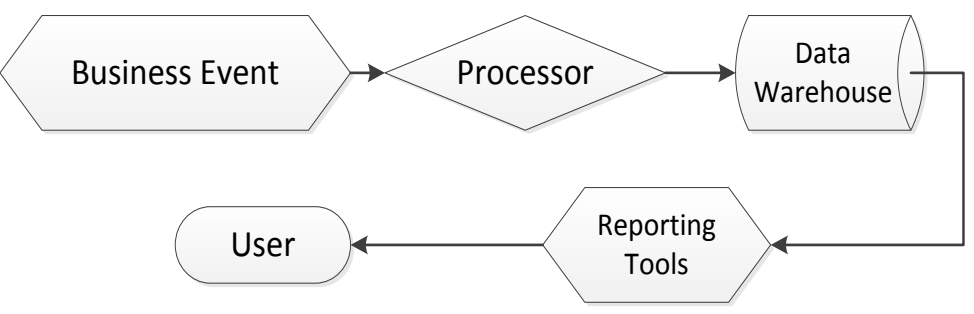

Fig.3: Business event-driven program flow

Software architecture, we choose B / S structure, with simple operation, easy maintenance

Centralized approach using distributed data set, this approach can not only reduce the backbone network bandwidth requirements, but also to meet the data sharing, open information integration requirements.

Network architecture use the Internet, the use of off-site intranet way to ensure the security and sharing of data. 
The purpose of accounting is to build an information system to achieve internal highly integrated, shared network accounting information system that can include the following modules:

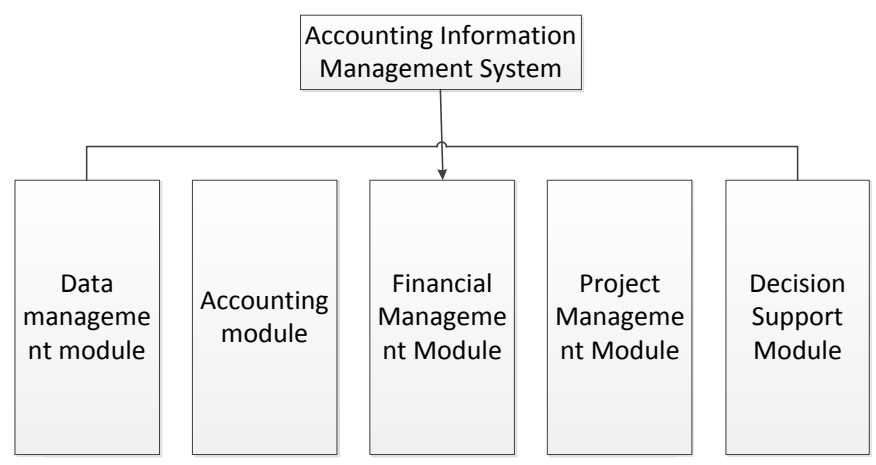

Fig.4: Module Design

As can be seen from the figure, the core function modules include: basic data module, accounting module, financial management module, project management module, the decision support module.

The overall framework of the relationship between the system and the module can be shown in Figure 5.

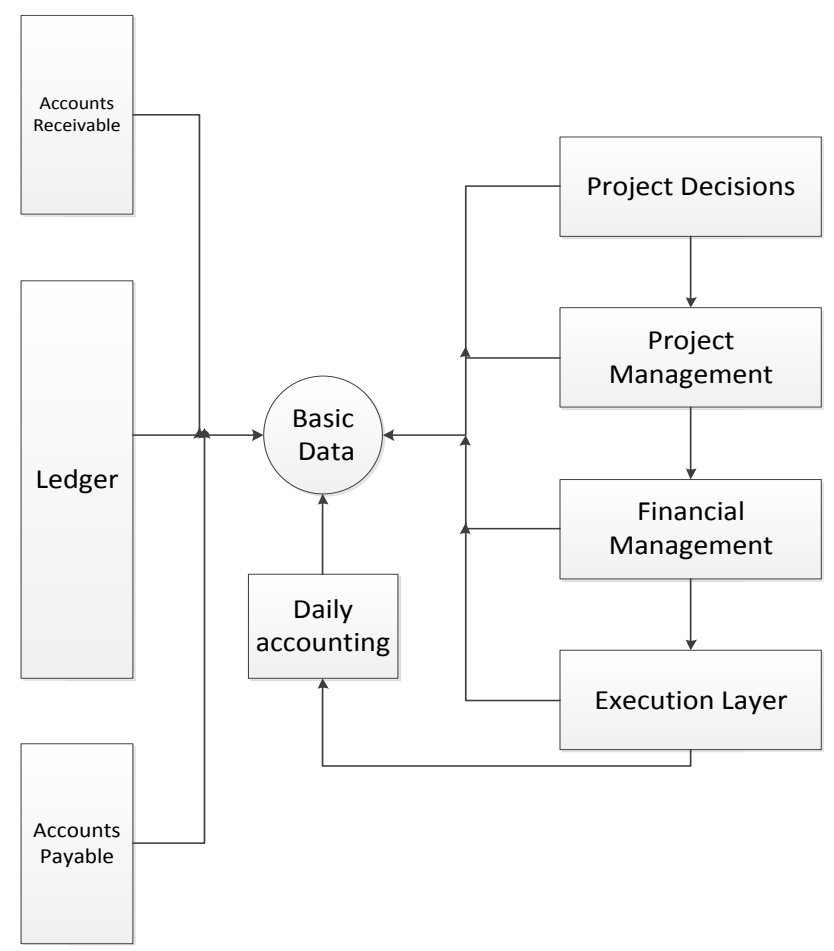

Fig .5: System Framework

Based on the above two block diagram, we explain the basic functionality of each module under in detail.

The Basic data module is equivalent to a modular system administrators use to achieve corporate accounting information system setup and management functions.

Accounting for the module to achieve wage, basic accounting of fixed assets, accounts payable, general ledger, reports, and other functions, these functions to achieve credentials by building event rules database automatically generated in real time.

Financial Management module enables business manager's real-time control business capital budget, capital control, cost management and other functions.

Project Management module enables businesses to project various departments reporting, approval, issued, planning, tendering, contracting, implementation and acceptance, the whole process of the evaluation process of online management. 


\section{Driven Design}

Accounting information system under network environment uses an event-driven process should approach alternative to the traditional function of the driving. Event-driven: when business events, according to the data processing rules, the business sector business event data into the database for business. Business event data in the database is only after the initial processing of the source data. When the user of the information wants to retrieve information from the system, the information users enter information processing code. The system starts the appropriate information processing procedures, business information database processing, and the results in real-time feedback to the information users. Enterprise database systems by each information system integration, making the raw data collected by decentralized, and centralized data processing and storage, in order to achieve the financial and operational synergies.

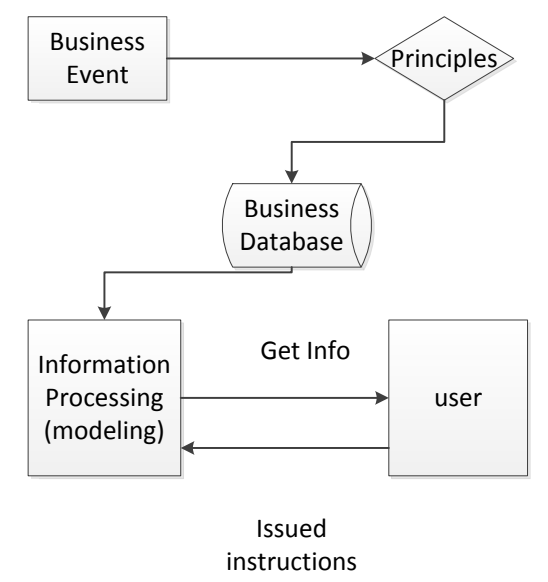

Fig .6: Driven Design

Accounting information systems using event-driven process approach has the following characteristics:

(1)Event-driven approach is based on business events (business activity) rather than user-based view of information. The focus of attention focused on business events, changing the operating range of accounting. System change not only record company's assets, liabilities and equity event, but who want to get records management plan, control and evaluation of the event.

(2)Shared source database. The decentralized system architecture logically centralized multiple databases, different levels of support, comprehensive information needs. After the events in accordance with the rules of business on the business and financial data integrated collection and storage, you can create a comprehensive database to share. Uniform Code of raw data, can meet all users outside the enterprise to share the information.

(3)Integration of information processing and real-time control.

(4)Support simplify the process and changes in accounting information systems processes.

\section{Database Design}

When you define a data structure, you should consider the relationship between the data. Data relationships can be used to build the application process used in the data table, that is to say the data source. Data sheet contains the application and maintenance of data records that describe the basic structure of the organization and its activities.

In the design, we have established four entities, that is to say: Resources, events, participants and locations.

According to the relationship between the entities can be established following several data tables.

Table 1: Inventory Database Table

\begin{tabular}{|c|c|c|c|c|c|c|}
\hline $\begin{array}{c}\text { Number of Raw } \\
\text { materials }\end{array}$ & Specifications & initial number & $\begin{array}{c}\text { Place } \\
\text { Order }\end{array}$ & Price & $\begin{array}{c}\text { price in } \\
\text { contract }\end{array}$ & \begin{tabular}{c} 
Location \\
\hline Primary key
\end{tabular} \\
\hline
\end{tabular}


Table 2: Cash Database Table

\begin{tabular}{|c|c|c|c|c|c|c|}
\hline Number of Cash & Account Type & initial overage & Overage now & Time & Location & \\
\hline Primary key & & & & & & \\
\hline
\end{tabular}

Table 3: The purchaser Data Sheet

\begin{tabular}{|c|c|c|c|c|c|c|}
\hline $\begin{array}{c}\text { Number } \\
\text { Of Single } \\
\text { requisition }\end{array}$ & Purchase Time & Check & $\begin{array}{c}\text { The number of } \\
\text { reviewer }\end{array}$ & $\begin{array}{c}\text { number of Procurement } \\
\text { people }\end{array}$ & Location & \\
\hline Primary key & & & & & & \\
\hline
\end{tabular}

Table 4: Accounting personnel data sheets

\begin{tabular}{|c|c|c|c|c|c|c|}
\hline Number of staff & Name & Age & Department & Skill & Sex & \\
\hline Primary key & & & & & & \\
\hline
\end{tabular}

\section{Business Process Design}

Figure systems business processes are as follows:

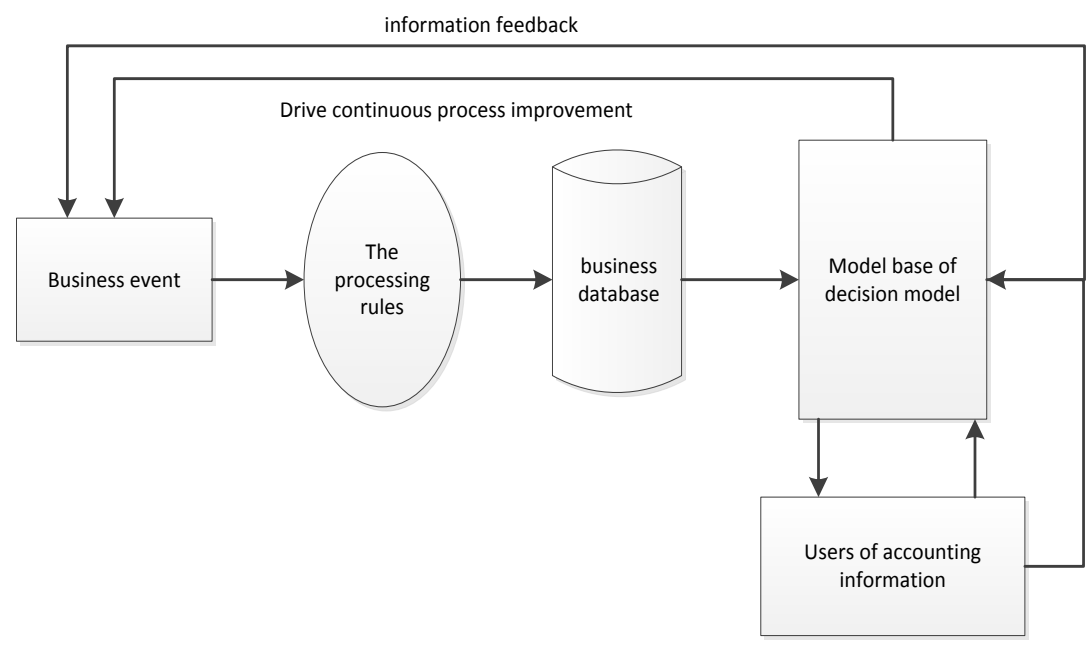

Fig .7: the accounting information system under the environment of the network

\section{Conclusions}

This paper analyzes the network environment, the accounting system of enterprises should be how to build to accommodate the increasing competition in the market. Accounting information systems can help corporate decision-making, management, and timely execution level resource sharing, decision making, decision execution, it is a highly efficient tool for enterprise accounting system.

\section{References}

[1] Liu Mingfei. Manual accounting information system and computerized accounting information system integration to explore [J]. Journal of business accounting, 2014, (7):128-129.

[2] Lu Shu jie, liu hang, Yang Ning etc. Auxiliary accounting application strategy research in accounting information system [J]. Journal of China commerce and trade, 2014, (13):109-110.

[3] Chen Yan. Extraction under the ERP for small and medium-sized enterprise internal control of accounting information system [J]. Value engineering, 2014, (8):191-192.

[4] Icy Lin. Based on the Internet of things under the perspective of accounting information system

[5] Xie Huobao, Zhang Xi. The construction of the era of big data enterprise ERP system and the accounting information system integration for Su Ningyun business - for example [J]. Journal of finance and accounting, 2014, (2):18-20. 
[6] Ma Yingjuan. Small and medium-sized enterprise accounting information system under the network environment reconstruction research [J]. Journal of development studies, 2013, (1): 153156. DOI: 10. 3969/j.issn. 1003-4161. 2013.01.034.

[7] Wang hong, Zhao Xuejin. Financial accounting information system in ERP environment research on internal control and risk management [J]. Friends of the accounting, 2013, (25): 55-57. DOI: 10.3969/j. issn.1004-5937. 2013. 25.016. 